\title{
Synthesis and properties of new polyimide-silica hybrid films through both intrachain and interchain bonding
}

\author{
Cheng-Tyng Yen ${ }^{\mathrm{a}}$, Wen-Chang Chen ${ }^{\mathrm{a}, \mathrm{b}, *}$, Der-Jang Liaw ${ }^{\mathrm{c}}$, Hsin-Yi Lu ${ }^{\mathrm{c}}$ \\ ${ }^{a}$ Department of Chemical Engineering, National Taiwan University, No. 1, Sec. 4, Roosevelt Road, Taipei 106, Taiwan, ROC \\ ${ }^{\mathrm{b}}$ Institute of Polymer Science and Engineering, National Taiwan University, Taipei 106, Taiwan, ROC \\ ${ }^{\mathrm{c}}$ Department of Chemical Engineering, National Taiwan University of Science and Technology, Taipei 107, Taiwan, ROC
}

Received 8 July 2003; received in revised form 3 September 2003; accepted 4 September 2003

\begin{abstract}
In this study, the new polymer-silica hybrid materials were prepared based on the organo-soluble polyimides of $4,4^{\prime}$ hexafluoroisopropylidenediphthalic anhydride (6FDA) and four diamines. 3-Aminopropyl trimethoxysilane (APrTEOS) and $\gamma$ glycidyloxypropyltrimethoxysilanes (GOTMS) were used to increase the intrachain chemical bonding and interchain hydrogen bonding between the polyimide and silica moieties, respectively. The chemical interaction would significantly affect the morphologies and properties of the prepared films. Highly homogeneous hybrid thin films were obtained according to the studies of atomic force microscopy and TEM. The silica size observed by the TEM picture was smaller than $5 \mathrm{~nm}$. The thermal properties of the organo-soluble polyimides were significantly enhanced by hybridizing only $6.30-7.99 \mathrm{wt} \%$ of silica. The intrachain chemical bonding could effectively enhance the coefficient of thermal expansion in comparison with the interchain interaction. Low dielectric constants in the range of 2.85-3.73 were obtained for the prepared hybrid films. The refractive indices of the prepared materials could be tuned through the polyimide structure or the silica content. The optical losses of the planar waveguides based on the prepared polyimides and their hybrids at $1310 \mathrm{~nm}$ were in the range of $0.5-2.7 \mathrm{~dB} / \mathrm{cm}$, which were mostly due to the higher harmonics of the aromatic $\mathrm{C}-\mathrm{H}$ vibration and the extrinsic loss. The prepared polyimide-silica hybrid materials could have potential applications for microelectronics or optical communications.

(C) 2003 Elsevier Ltd. All rights reserved.
\end{abstract}

Keywords: Polyimide; Silica; Hybrid

\section{Introduction}

Organic-inorganic hybrid materials have been recognized as a new class of advanced materials because of the versatile approaches on synthesis, processing, and tunable properties [1,2]. The size of the inorganic segment in the hybrid materials could be controlled by the synthetic method (e.g. reverse micelles) or by the combination of synthesis and processing (e.g. sol-gel/spin coating/curing). Recently, several applications of hybrid materials in optoelectronic devices have been reported, including thin film transistors [3], solar cells [4], light-emitting diodes [5], optical waveguides [6], low dielectric constant materials [7], and high refractive index thin films [8].

\footnotetext{
* Corresponding author. Address: Department of Chemical Engineering, National Taiwan University, No. 1, Sec. 4, Roosevelt Road, Taipei 106, Taiwan, ROC. Tel.: + 886-2-23628398; fax: + 886-2-23623040.

E-mail address: chenwc@ms.cc.ntu.edu.tw (W.C. Chen).
}

Polyimides have been widely used in optoelectronics. However, the thermal and mechanical properties are required to be enhanced if high temperature processing or integrating with other inorganic materials is required. One possible solution is to prepare polyimide-silica hybrid materials. There were several classes of polyimide-silica hybrid materials reported in the literature [6,7,9-22], which show improved thermal stability and mechanical strength in comparison with their parent polyimides. One of the primary problems for preparing the hybrid materials is the phase separation between the organic and inorganic moieties. To overcome the phase separation of polyimide and inorganic oxide, the approach of either short chain polyimide segment [6], coupling agents [6,10-22], or the combination of both approaches [6] were used to enhance the compatibility by increasing the density of coupling sites.

The earlier reports on the preparation of polyimidesilica were from the poly(amic acid) precursors [9-21]. 
Recently, Shang et al. reported the synthesis of polyimidesilica hybrid materials from organo-soluble polyimides [22]. The coupling agent used by Shang et al. [22], $\gamma$ glycidyloxypropyltrimethoxysilanes (GOTMS), could have interchain hydrogen bonding with the carbonyl group of the dianhydride moiety. Thus, the silica size in the prepared hybrid materials was controlled in the range of $30 \mathrm{~nm}-$ $1.5 \mu \mathrm{m}$. For further narrowing the silica domain in the nanosize range, the introduction of the intrachain coupling might be necessary besides the interchain approach used by Shang et al. [22] Besides, it will be necessary to develop a new general reaction scheme for preparing highly homogeneous hybrid materials from organo-soluble polyimides.

In this study, new polymer-silica hybrid materials were prepared based on organo-soluble polyimides from 4, $4^{\prime}$ hexafluoroisopropylidenediphthalic anhydride (6FDA) and four diamines developed by Liaw et al. [23-26], as shown in Fig. 1. A dianhydride end-capped polyimides (Ia-Id) were obtained first and then reacted with 3-aminopropyl trimethoxysilane (APrTEOS). In the following, tetramethoxysilane (TMOS) was reacted with the APrTEOS end-capped polyimides to form the polyimide-silica materials (IIa-IId). Then, GOTMS was used as a compatibilizer to enhance the interchain interaction of the prepared polyimide-silica materials (IIIa-IIId). The APrTEOS and GOTMS were used for the intrachain covalent bonding and interchain hydrogen bonding between the polyimide and silica moieties, respectively, as shown in Fig. 2. The molecular structure and morphology of the prepared polyimide-silica hybrid films were characterized by FTIR, TEM, and atomic force microscopy (AFM). The thermal, dielectric, and optical properties of the prepared hybrid films were studied and correlated with the molecular structure.

\section{Experimental}

\subsection{Materials}

1,4-Bis(4-aminophenoxy)-2-tert-butylbenzene (BATB), 2,2'-dimethyl-4,4'-bis(4-aminophenoxy)phenyl (DBAPB), 2,2-bis[4-(4-aminophenoxy)phenyl] hexafluoropropane (BAPPH) and 2,2'-bis[4-(4-aminophenoxy)phenyl]norbornane (BAPN) were synthesized and purified according to the previous reported methods [23-26]. 4,4'-Hexafluoroisopropylidenediphthalic anhydride (6FDA, Aldrich, 99\%), $N, N$-dimethylacetamide (DMAc, Tedia, 99\%), 3-aminopropyltriethoxysilane (APrTEOS, Aldrich, 97\%), tetramethyl orthosilicate (TMOS, Aldrich, 99\%), and 3-glycidoxypropyltrimethoxysilane (GOTMS, Aldrich, 98\%) were purchased and used without further purification.

\subsection{Preparation of organo-soluble polyimides $(\boldsymbol{I} \boldsymbol{a}-\boldsymbol{I d})$}

The synthesis of organic-soluble polyimides, Ia-Id, used a similar method as reported in Ref. [6]. The molar ratio of dianhydride and diamine was kept on 5:4 to give a dianhydride end-capped polyimide, and a moderate molecular weight. Here, synthesis of Ia was given as an example. Diamine $(1.394 \mathrm{~g}, 4 \mathrm{mmol})$, BATB, was first dissolved into $20.387 \mathrm{~g}$ of DMAc. Then, $3.554 \mathrm{~g}(5 \mathrm{mmol})$ of dianhydride, 6FDA, was slowly added into the above solution with vigorous stirring and purged with nitrogen. The mixture solution was allowed to react for $24 \mathrm{~h}$ at room temperature to form a viscous and homogeneous poly(amic acid) (PAA) solution. Chemical imidization of the above prepared PAA was carried out by adding a mixture of $2.756 \mathrm{~g}$ of acetic anhydride (27 mmol), $2.732 \mathrm{~g}$ of triethylamine $(27 \mathrm{mmol})$, and $31.105 \mathrm{~g}$ of DMAc, into the abovementioned PAA solution with vigorous stirring for $30 \mathrm{~min}$ at room temperature, and then in a $60{ }^{\circ} \mathrm{C}$ silicon oil bath for another $24 \mathrm{~h}$. The homogeneous solution was subsequently poured into de-ionized water, precipitated, filtered out and dried at $160{ }^{\circ} \mathrm{C}$ overnight under reduced vacuum to obtain the 6FDA end capped polyimide Ia. The polyimides Ib-Id were prepared by a similar procedure as Ia.

\subsection{Preparation of precursor solutions for the polyimide/silica hybrid films, IIa-IId}

The preparation of the polyimide-silica solution, IIa, was described here as an example. The above-prepared 6FDA/BATB polyimide, Ia, of $1.0 \mathrm{~g}$ was re-dissolved into $6.384 \mathrm{~g}$ of DMAc to form a $15 \mathrm{wt} \%$ polyimide solution. APrTEOS $(26.6 \mathrm{mg}$ ) was added to the solution and allowed to react for $4 \mathrm{~h}$ at room temperature. To the mixture, $100 \mathrm{mg}$ of TMOS was added and stirred for $15 \mathrm{~min}$. Then, $31 \mathrm{mg}$ of deionized water and $10 \mathrm{mg}$ of $0.01 \mathrm{M} \mathrm{HCl}$ solution were added and allowed to react at room temperature for $24 \mathrm{~h}$ to give a homogeneous solution. The preparation of the other polyimide/silica solutions, IIb-IId, was prepared by a similar procedure as that of IIa.

\subsection{Preparation of precursor solutions for the GOTMS compatiblized polyimide/silica hybrid films, IIIa-IIId}

To the above prepared precursor solution of IIa-IId, a proper amount of GOTMS (GOTMS:TMOS = 1:5 in weight) was added and stirred at room temperature for $24 \mathrm{~h}$ to give a homogeneous GOTMS compatiblized polyimide/silica solution for the hybrid materials, IIIaIIId.

\subsection{Preparation of polyimide films, $\mathbf{I a}-\boldsymbol{I} \boldsymbol{d}$, and their corresponding polyimide/silica hybrid thin films, IIa-IId and IIIa-IIId}

APrTEOS solution (0.1 wt \%) (dissolved in 1-methoxy-2propanol) used as an adhesion promoter for the prepared polyimides was spin-coated on a silicon wafer at $3000 \mathrm{rpm}$ for $10 \mathrm{~s}$, and cured at $105^{\circ} \mathrm{C}$ for $90 \mathrm{~s}$. The prepared 

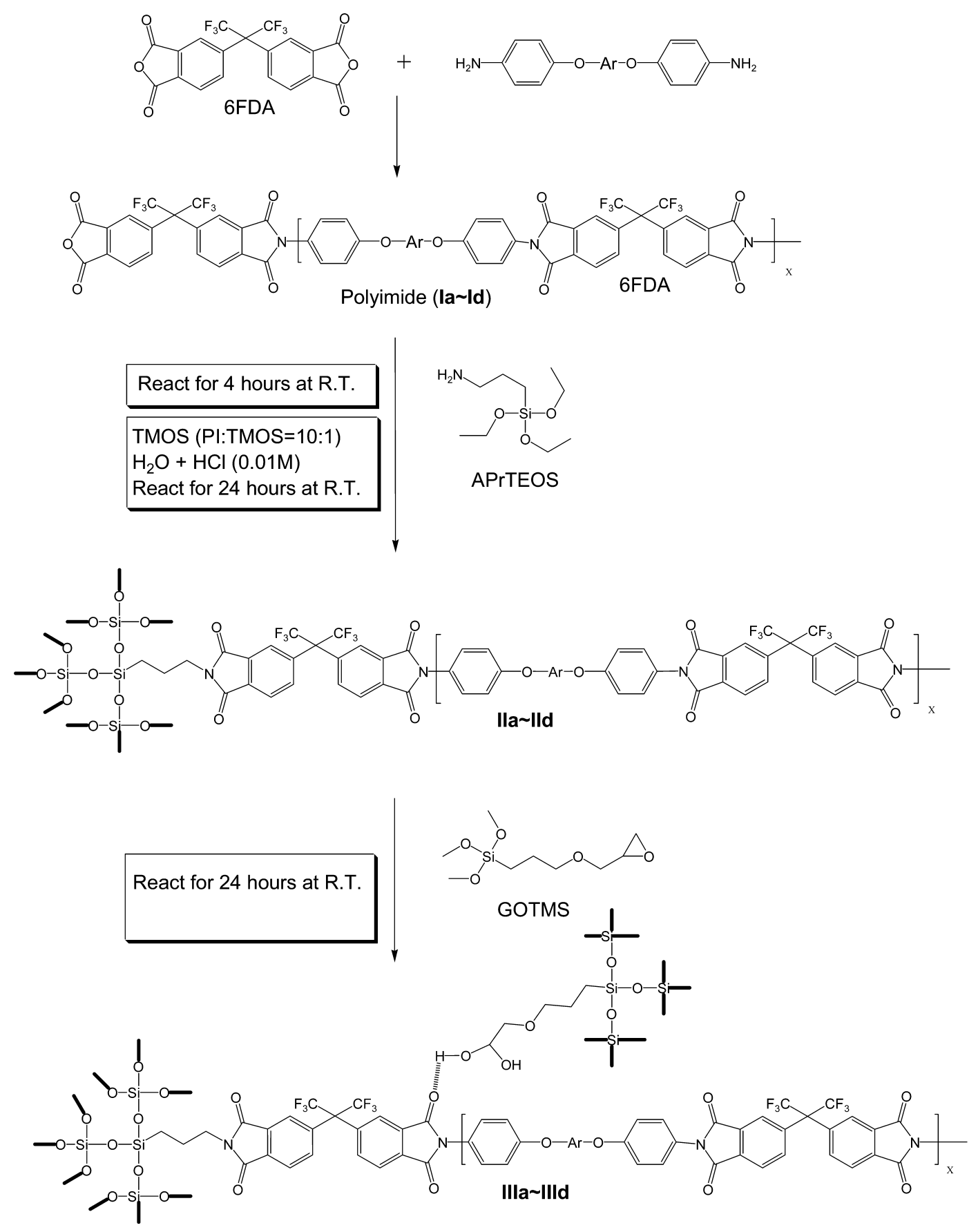

Ar:

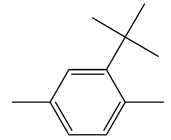

(a) BATB

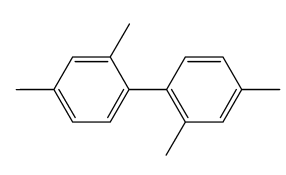

(b) DBAPB

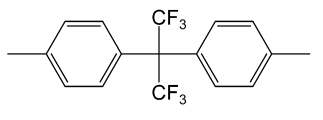

(c) BAPPH

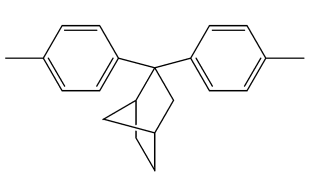

(d) BAPN

Fig. 1. Reaction scheme for preparing organo-soluble polyimide/silica hybrid materials, IIIa-IIId. 

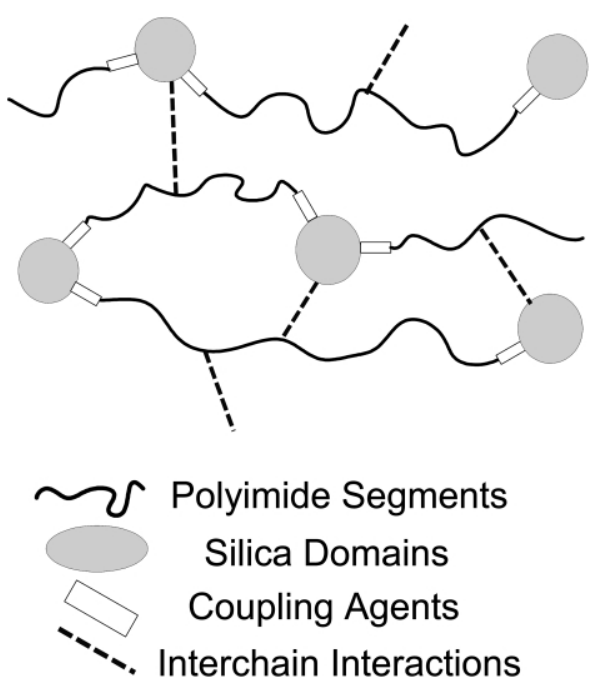

Fig. 2. Illustration of the bonding and interactions between organic and inorganic moieties in the prepared hybrid materials.

precursor solution ( $15 \mathrm{wt} \%$ ) was filtered by a $0.2 \mu \mathrm{m}$ filter prior to use, and then spin-coated on top of the APrTEOS film at $3000 \mathrm{rpm}$ for $20 \mathrm{~s}$. The thin film was then obtained after baking it at $80{ }^{\circ} \mathrm{C}$ on a hot plate for $1 \mathrm{~h}$ and then cured in a nitrogen purged furnace box up to $350{ }^{\circ} \mathrm{C}$ at the ramp rate of $5{ }^{\circ} \mathrm{C} / \mathrm{min}$, and held on $350{ }^{\circ} \mathrm{C}$ for $30 \mathrm{~min}$. The prepared polyimide/silica hybrid thin films were used for characterizations of FTIR, refractive index measurement, AFM, dielectric constant measurement, and transmission electron microscopy (TEM). The samples for obtaining the UV/visible spectra were prepared by the similar processes but on a clean quartz substrate. The samples for TGA, DSC, TMA, and near-infrared (NIR) spectra characterization were prepared by casting on a Teflon substrate. For the optical waveguide characterization of the prepared materials, the silicon dioxide cladding layer with the thickness of $1.5 \mu \mathrm{m}$ was prepared on a silicon wafer first. Then, the guiding layer was prepared from a $15 \mathrm{wt} \%$ of the polyimide or polyimide/silica precursor solution on top of the above silicon dioxide. APrTEOS solution (0.1 wt $\%$ ) (dissolved in 1-methoxy-2-propanol) was used as the adhesion promoter before the precursor solution coated.

\subsection{Synthesis of precursor solutions for GOTMS compatiblized polyimide/silica hybrid films, $\boldsymbol{I V \boldsymbol { b }}$}

The above prepared 6FDA/DBAPB polyimide, $\mathbf{I b}$, of $1 \mathrm{~g}$ was dissolved into $6.384 \mathrm{~g}$ of DMAc to form a $15 \mathrm{wt} \%$ polyimide solution. To the solution, $100 \mathrm{mg}$ of TMOS was added and stirred for $15 \mathrm{~min}$. Then, $31 \mathrm{mg}$ of deionized water and $10 \mathrm{mg}$ of $0.01 \mathrm{M} \mathrm{HCl}$ solution were added and stirred for $30 \mathrm{~min}$. After that, $20 \mathrm{mg}$ of GOTMS was added and allowed to react at room temperature for $24 \mathrm{~h}$ to obtain a precursor solution for IVb as shown in Fig. 3. The film of IVb was prepared similar to those for Ib-IIIb.

\subsection{Characterization}

The FTIR and NIR spectra of the prepared polymer films were recorded by a DIGILAB FTS-3500GX spectrophotometer. The molecular weight distribution of the prepared polymers, Ia-Id, was determined by a gel permeation chromatography (GPC) equipped with PLgel $5 \mu \mathrm{m}$ MIXED-C and D columns, a RI detector, and the elution solvent of THF at $1 \mathrm{ml} / \mathrm{min}$.

A Digital Instrument Model DI-5000 atomic force microscope (AFM) was used to probe the surface morphology of the prepared thin films. The TEM diagram of the prepared hybrid film was obtained from the JEOL (model number:2002-EX). The thermal decomposition temperatures $\left(T_{\mathrm{d}}\right)$ of the prepared materials were characterized by a TA Instrument TGA 951 thermogravimetric analyzer (TGA) at a heating rate of $20^{\circ} \mathrm{C} / \mathrm{min}$ from room temperature to $900{ }^{\circ} \mathrm{C}$. Glass transition temperature $\left(T_{\mathrm{g}}\right)$ was characterized by a TA Instrument DSC $910 \mathrm{~S}$ differential scanning calorimeter (DSC) at a heating rate of $10{ }^{\circ} \mathrm{C} / \mathrm{min}$ from room temperature to $350{ }^{\circ} \mathrm{C}$. A TA2940 thermomechanical analyzer (TMA) was used to characterize $T_{\mathrm{g}}$ and coefficient of thermal expansion (CTE) at a heating rate of $10{ }^{\circ} \mathrm{C} / \mathrm{min}$ from room temperature to $350{ }^{\circ} \mathrm{C}$.

The dielectric constant of the prepared materials was determined as below. An aluminum layer of $5000 \AA$ was coated on the prepared thin film by a ULVAC EBX-6D thermal evaporator with an attached mask, and probed by a Keithly $590 \mathrm{C}-\mathrm{V}$ analyzer with a sweeping frequency of $100 \mathrm{kHz}$ to determine the dielectric constant. A Metricon Model 2100 prism coupler was used to measure the film thickness and refractive indices of the prepared thin films at the wavelength of $1319 \mathrm{~nm}$. The UV-visible spectra of the prepared polymer films were recorded by a Jasco V-570 spectrophotometer. The optical losses of the prepared waveguides at the wavelength of $1310 \mathrm{~nm}$ were measured by a cut-back method according to our previous report [6].

\section{Results and discussion}

Fig. 4 shows the FTIR spectra of the prepared materials, Ib-IIIb. The characteristic imide groups are observed at the following peaks: $1785 \mathrm{~cm}^{-1}(\mathrm{C}=\mathrm{O}$ asym. str. $), 1727 \mathrm{~cm}^{-1}$ ( $\mathrm{C}=\mathrm{O}$ sym. str.), and $1379 \mathrm{~cm}^{-1}$ (C-N str.). The $\mathrm{C}-\mathrm{NH}$ stretching band around $1660 \mathrm{~cm}^{-1}$ was not observed in Fig. 4 , which indicates the successful chemical imidization of the prepared Ib-IIIb. The strong absorption band about $1180-1320 \mathrm{~cm}^{-1}$ resulted from the $-\mathrm{CF}_{3}$ group of the 6FDA moiety, which is overlapped with the diphenyl ether band at $1240 \mathrm{~cm}^{-1}$. The $\mathrm{Si}-\mathrm{O}-\mathrm{Si}$ stretching band should be observed at $1100 \mathrm{~cm}^{-1}$ but is overlapped with the in-plane $\mathrm{C}-\mathrm{H}$ bending vibration band. Therefore, the differences between Ib and IIb-IIIb could not be clearly observed because of the low silica content in the prepared hybrid materials. Note that the silica contents in the polyimide/ 


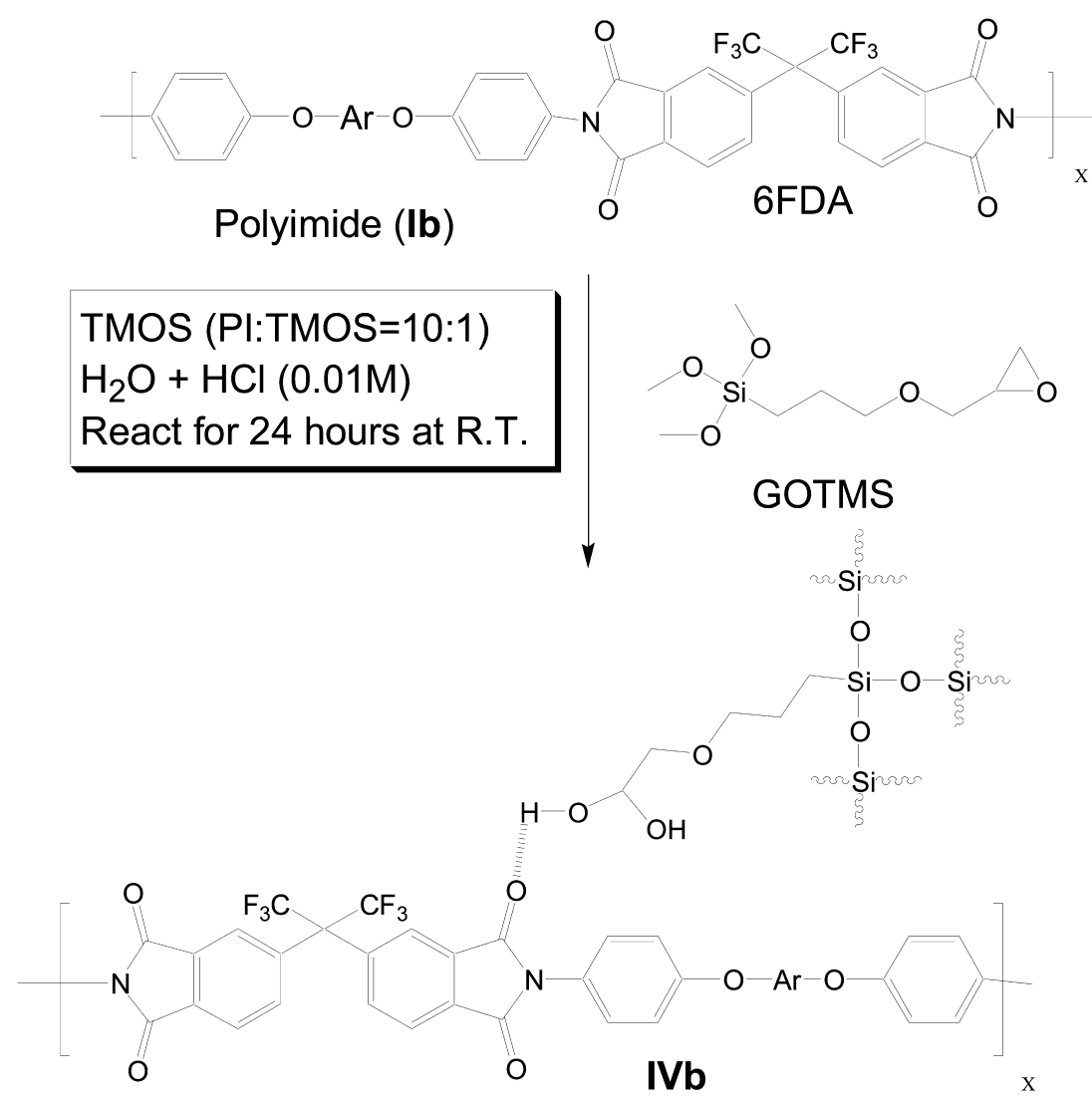

Fig. 3. Reaction scheme for preparing IVb.

silica hybrid thin films are estimated to be from 6.30 to $7.99 \mathrm{wt} \%$ by assuming the full condensation of TMOS, APrTEOS, and GOTMS, as shown in Table 2. A very weak $\mathrm{OH}$ band around $3400-3800 \mathrm{~cm}^{-1}$ suggests the successful condensation of the silica moiety.

The number averaged molecular weight and polydisper- sion $\left(M_{\mathrm{n}}, M_{\mathrm{w}} / M_{\mathrm{n}}\right)$ of the prepared polyimides are as below: Ia (18 427, 2.25); Ib (32 460, 2.09); Ic (8434, 1.93); and Id $(8429,1.75)$. The moderate molecular weight resulted from the unequal mole ratio of dianhydride and diamine. If the prepared polyimides had a high molecular weight, the coupling efficiency between the polyimide and silica moiety

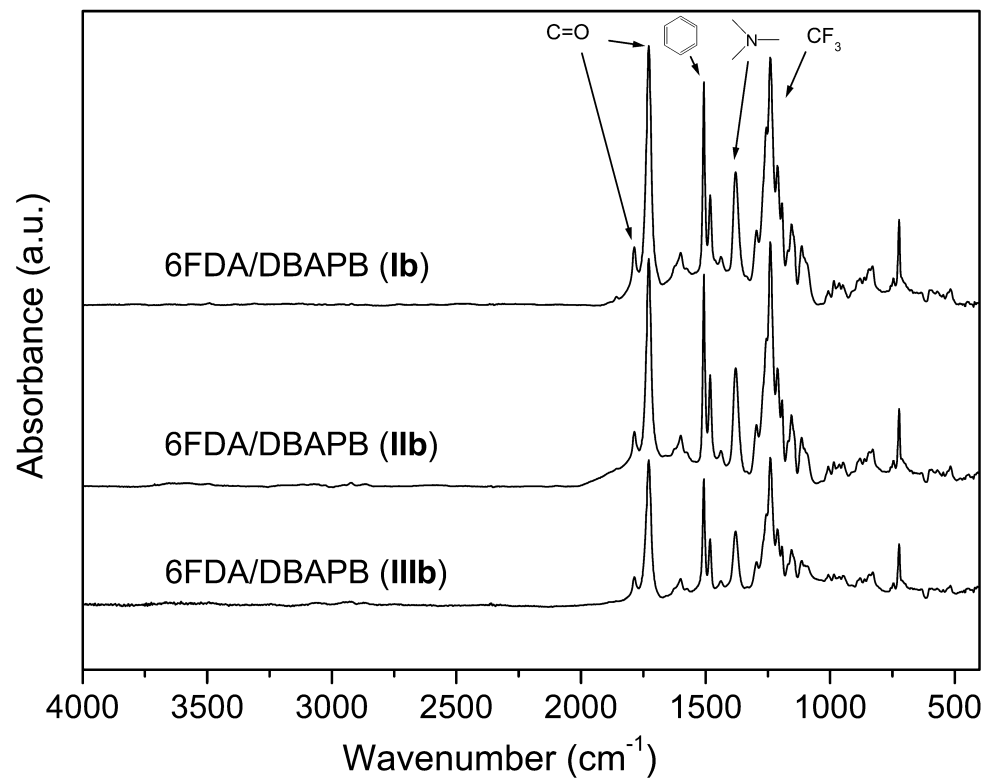

Fig. 4. FTIR spectra of the prepared 6FDA/DBAPB polyimide (Ib) and its corresponding polyimide/silica hybrids (IIb and IIIb). 
would be low and resulted in macro-phase separation. On the contrary, the thermal and mechanical properties would not be enhanced if the molecular weight of the prepared polyimide was too low.

The thickness and surface roughness of the prepared films are shown in Table 1 . The surface roughness, $R_{\mathrm{a}}$, and $R_{\mathrm{q}}$, of the prepared films are all smaller than $0.6 \mathrm{~nm}$, which are smaller than $0.1 \%$ of the film thickness. Hence, the prepared film had excellent surface planarization. Fig. 5 shows the TEM diagram of the prepared film IIIb, which illustrates the silica domain size smaller than $5 \mathrm{~nm}$, which is much smaller than the reported silica domain from $30 \mathrm{~nm}$ to several $\mu \mathrm{m}$ for the polyimide/silica hybrid materials [8-11, 17,19-20,22]. Large silica domain might deteriorate the optical, thermal and mechanical properties of the prepared hybrid materials. The present approach of combining the interchain and intrachain interaction successfully limited the silica size and could be used to produce highly homogeneous hybrid films. The incorporated silica fraction is in the range of $6.30-7.99 \mathrm{wt} \%$ and thus the surface roughness and silica size of the prepared hybrid films are similar.

The thermal decomposition temperature $\left(T_{\mathrm{d}}\right)$, glass transition temperature $\left(T_{\mathrm{g}}\right)$, and CTE of the prepared materials are shown in Table 2. Fig. 6 shows the TGA curves of the prepared materials, Ib-IVb. The order of $T_{\mathrm{d}}$ is IIIb $>$ IIb $>$ IVb $\cong$ Ib. The intrachain chemical bonding by the APrTEOS could enhance the $T_{\mathrm{d}}$ more effective than the interchain hydrogen bonding by the GOTMS, which is similar to that reported in the literature [19]. However, the difference in the $T_{\mathrm{d}}$ between polyimide and polyimide/silica was not remarkable and might be because the thermal decomposition was from the chain scission of the polyimide moiety and the low silica content could not be effective for inhibiting thermal decomposition of polyimide moieties.

Fig. 7 shows the TMA curves of the prepared materials,

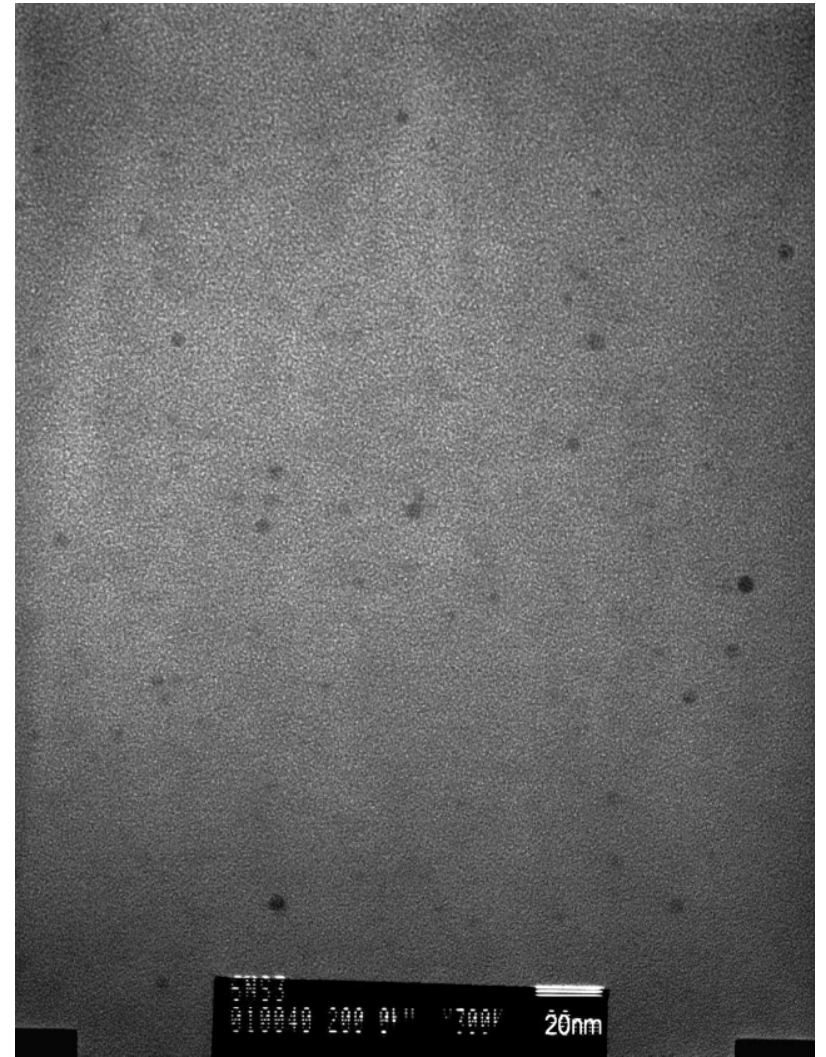

Fig. 5. TEM diagram of the prepared hybrid material, IIIb

Ib-IVb. The order of $T_{\mathrm{g}}$ determined from TMA is IIIb $\cong \mathbf{I I b}>\mathbf{I V b} \cong \mathbf{I b}$, which can be explained as below. $T_{\mathrm{g}}$ is generally known as the onset temperature as large groups in the main chain start their segmental motion. For the case of IIb and IIIb, the chain end of the polyimide moiety is covalently bonded to the silica domain through the APrTEOS, which might restrict the segmental mobility and thus enhance the $T_{\mathrm{g}}$. However, the interchain hydrogen

Table 1

The physical properties of the prepared polyimides and the polyimide/silica hybrid films

\begin{tabular}{|c|c|c|c|c|c|c|c|c|c|}
\hline & Thickness (nm) & $\varepsilon^{\mathrm{a}}$ & $n_{1319 \mathrm{TE}}$ & $n_{1319 \mathrm{TM}}$ & $R_{\mathrm{q}}(\mathrm{nm})$ & $R_{\mathrm{a}}(\mathrm{nm})$ & $R_{\mathrm{LL}} / V^{\mathrm{b}}\left(\mathrm{cm}^{-3}\right)$ & $\mathrm{C}-\mathrm{H}$ number density ${ }^{\mathrm{b}}\left(10^{22} \mathrm{~cm}^{-3}\right)$ & $\alpha^{\mathrm{c}}(\mathrm{dB} / \mathrm{cm})$ \\
\hline 6FDA/BATB (Ia) & 1133 & 3.16 & 1.5922 & 1.5872 & 0.41 & 0.32 & 0.321 & 4.45 & 2.7 \\
\hline 6FDA/BATB (IIa) & 1628 & - & 1.5773 & 1.5724 & 0.57 & 0.46 & - & - & 2.1 \\
\hline 6FDA/BATB (IIIa) & 1059 & 3.22 & 1.5685 & 1.5651 & 0.25 & 0.200 & - & - & 1.9 \\
\hline 6FDA/DBAPB (Ib) & 4197 & 3.05 & 1.5926 & 1.5864 & 0.41 & 0.28 & 0.326 & 4.06 & 2.4 \\
\hline 6FDA/DBAPB (IIb) & 3727 & - & 1.5909 & 1.5724 & 0.35 & 0.28 & - & - & 1.7 \\
\hline 6FDA/BAPPH (Ic) & 925 & 2.85 & 1.5685 & 1.5651 & 0.38 & 0.28 & 0.313 & 3.23 & 1.2 \\
\hline 6FDA/BAPPH (IIc) & 1334 & - & 1.5542 & 1.5510 & 0.26 & 0.20 & - & - & 0.8 \\
\hline 6FDA/BAPPH (IIIc) & 835 & 2.91 & 1.5479 & 1.5423 & 0.31 & 0.26 & - & - & 0.5 \\
\hline 6FDA/BAPN (Id) & 1132 & 3.56 & 1.5859 & 1.5745 & 0.44 & 0.44 & 0.314 & 4.34 & 1.9 \\
\hline 6FDA/BAPN (IId) & 1135 & - & 1.5795 & 1.5712 & 0.35 & 0.35 & - & - & 1.1 \\
\hline 6FDA/BAPN (IIId) & 1133 & 3.73 & 1.5767 & 1.5676 & 0.30 & 0.30 & - & - & 1.3 \\
\hline
\end{tabular}

a Dielectric constant measured at $100 \mathrm{kHz}$.

b Calculated from Ref. 30.

c Optical loss measured at $1310 \mathrm{~nm}$. 
Table 2

The thermal properties of the prepared polyimides and the polyimide/silica hybrid materials

\begin{tabular}{lllllc}
\hline & $\begin{array}{l}\text { Silica content } \\
(\mathrm{wt} \%)\end{array}$ & $\begin{array}{l}T_{\mathrm{d}} \\
\left({ }^{\circ} \mathrm{C}\right)\end{array}$ & $\begin{array}{l}T_{\mathrm{g}} \\
\left({ }^{\circ} \mathrm{C}\right)^{\mathrm{a}}\end{array}$ & $\begin{array}{l}T_{\mathrm{g}} \\
\left({ }^{\circ} \mathrm{C}\right)^{\mathrm{b}}\end{array}$ & $\begin{array}{l}\mathrm{CTE} \\
\left(\mathrm{ppm} /{ }^{\circ} \mathrm{C}\right)\end{array}$ \\
\hline 6FDA/BATB (Ia) & - & 502 & 244 & 244 & 357.6 \\
6FDA/BATB (IIa) & 6.51 & 512 & 255 & 256 & 147.4 \\
6FDA/BATB (IIIa) & 7.16 & 517 & 259 & 268 & 24.1 \\
& & 517 & 247 & 270 & 292.6 \\
6FDA/DBAPB (Ib) & - & 523 & 264 & 279 & 64.3 \\
6FDA/DBAPB (IIb) & 6.30 & 527 & 266 & 279 & 26.9 \\
6FDA/DBAPB (IIIb) & 6.94 & 518 & 256 & 271 & 44 \\
6FDA/DBAPB (IVb) & 6.44 & 518 & 238 & 256 & 123.4 \\
& & 526 & 256 & 263 & 88.8 \\
6FDA/BAPPH (Ic) & - & 524 & 257 & 273 & 24 \\
6FDA/BAPPH (IIc) & 7.29 & 482 & 254 & 264 & 726.9 \\
6FDA/BAPPH (IIIc) & 7.92 & 507 & 268 & 273 & 266.7 \\
& & 515 & 271 & 271 & 16.6 \\
6FDA/BAPN (Id) & - & & & & \\
6FDA/BAPN (IId) & 7.36 & 7.99 & & &
\end{tabular}

a By DSC.
b By TMA.

bonding by the GOTMS could not limit the main chain segmental motion effectively and thus only enhance $T_{\mathrm{g}}$ slightly in the cases of IIb and Ib. Such a trend is also observed from the other prepared materials, as shown in Table 2.

Although the incorporation of the silica moiety does not enhance the $T_{\mathrm{d}}$ or $T_{\mathrm{g}}$ significantly, it reduced the CTE remarkably. The CTE of the prepared materials shows a significant difference from Table 2, which has a general trend of III $>$ II $>$ I. It suggests a significant difference in the intrachain chemical bonding and interchain hydrogen bonding of the prepared hybrid materials on the obtained CTE. The CTE of polyimide is generally influenced by the chain relaxation and orientation [27,28]. The out-of-plane CTE of the prepared polyimide films is in the range from 123.4 to $726.9 \mathrm{ppm} /{ }^{\circ} \mathrm{C}$, as shown in Table 2 . This large shrinkage of the prepared organo-soluble polyimide films

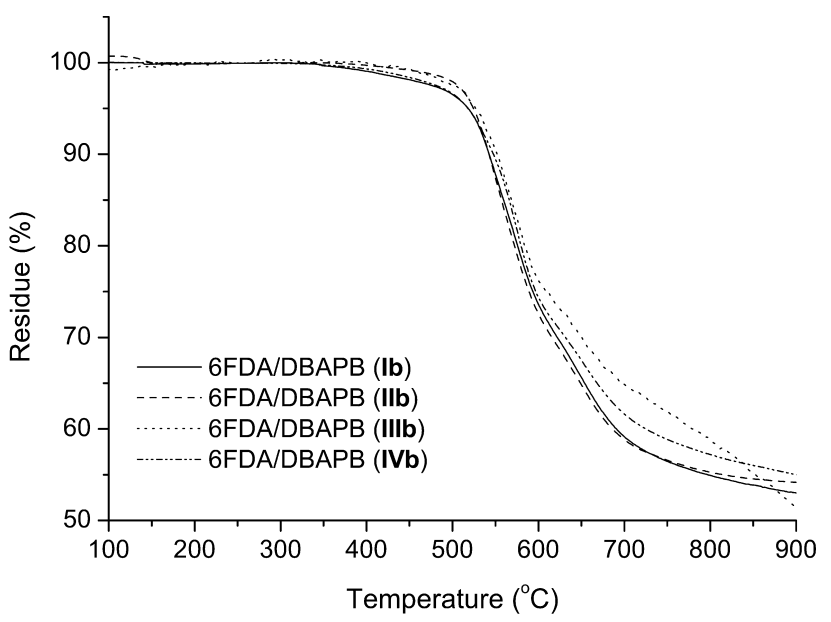

Fig. 6. TGA curves of the prepared 6FDA/DBAPB polyimide (Ib) and polyimide/silica hybrids (IIb-IVb).

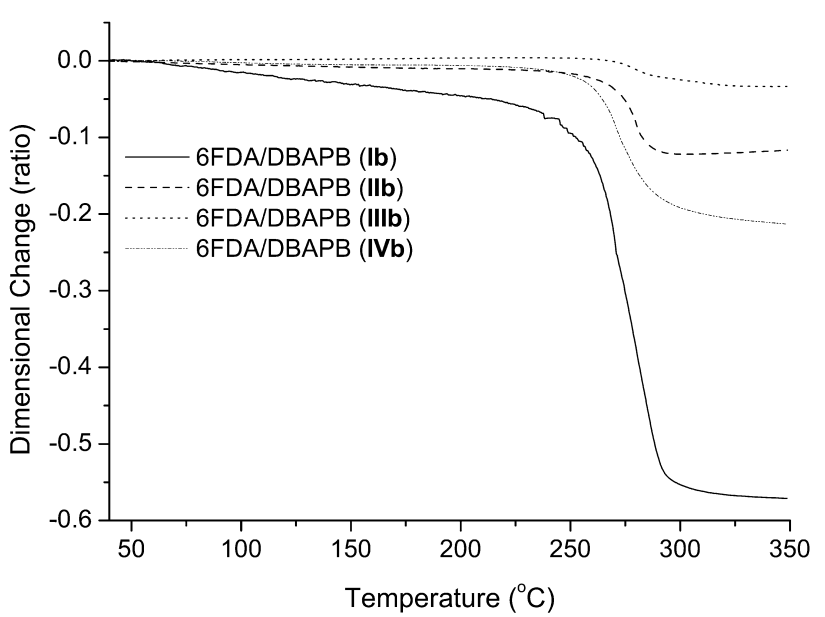

Fig. 7. TMA curves of the prepared 6FDA/DBAPB polyimide (Ib) and polyimide/silica hybrids (IIb-IVb).

(I) suggested by the CTE is probably because they have intrinsically more free volumes in the molecular structures than the rod-like polyimide, such as PMDA/ODA. Upon heating, the flexible main chains of the prepared polyimides (I) are significantly relaxed and orientated through the inplane direction, and induce the dimensional shrinkage in the out-of-plane direction. For the case of the polyimide-silica films (II), the chain end of the flexible polyimide moiety is 'fixed' by the silica moiety and thus significantly reduces the relaxation and orientation. By further incorporating the interchain compatibilizer, GOTMS, the chain relaxation and orientation of the polyimide moiety are further constrained, and thus obtain a low CTE for the materials of (III). Consequently, the CTE of the polyimide/silica hybrid films, (III), is the smallest among the studied materials of I-III, which is in the range of $16.6-41.6 \mathrm{ppm} /{ }^{\circ} \mathrm{C}$. These values are very close to much of the rod-like polyimides [29] despite the low loading of silica in this study.

Polyimides have been shown as one of the promising dielectric materials. The dielectric constants of the prepared polyimides (I) and their corresponding PI/silica hybrids (III) are shown in Table 1. The dielectric constants of the materials of I and III are in the range of 2.85-3.56 and $2.91-3.73$, respectively. It is well known that the incorporation of the fluorinated substituents into polymers could decrease the dielectric constant due to the low ratio of the molar polarizability over molar volume by the trifluoromethyl groups. Hence, the (Ic) and (IIIc) have the smallest dielectric constant in comparison with the other diamine based materials. The dielectric constants of the prepared polyimide/silica hybrid films (III) are higher in comparison with their parent polyimides (I) because of the inherent higher dielectric constant of silica. Although the incorporation of the silica moiety enhances the dielectric constant slightly, it enhances the thermal properties of the studied fluorinated polyimides for the possible microelectronic applications.

Fig. 8 shows the UV-visible absorption spectra of the 


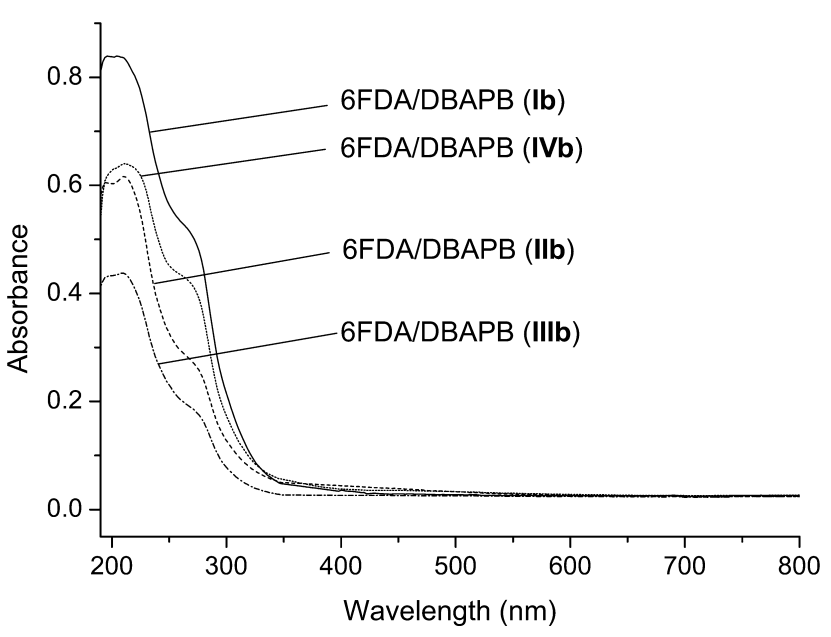

Fig. 8. UV-visible absorption spectra of the prepared films, Ib-IVb.

prepared polyimide films, $(\mathbf{I b})-(\mathbf{I V b})$. The prepared materials are highly transparent in the visible region. The formation of charge transfer complex results in the tailing around $350 \mathrm{~nm}$ of the spectrum of (Ib), which results in the yellowing of the films. By increasing the silica content, it reduces the density of the charge transfer band at $350 \mathrm{~nm}$ and thus increases the transparency for the cases of IIb and IIIb.

The refractive indices of the prepared materials (I)-(III) at the wavelengths of $1319 \mathrm{~nm}$ are shown in Table 1. It has a general trend in the order of the refractive index: 6FDA/ DBAPB (c) $<$ 6FDA/BAPN (d) <6FDA/BATB (a) $<6$ FDA/BAPPH (b). According to the Lorentz and Lorenz equation, the refractive index is generally proportional to the ratio of the molar refraction $\left(R_{\mathrm{LL}}\right)$ to the molar volume $(V)$. As shown in Table 1 , the trend of the obtained refractive index is in consistent with the $R_{\mathrm{LL}}$ to $V$. It suggests that the refractive index of the prepared polyimides could follow the Lorentz and Lorenz equation. The higher refractive index of the 6FDA/DBAPB (b) than that of the 6FDA/BATB (a) is attributed to the additional high molar refractive phenyl group in the diamine moiety of the (b). The large norbornane side group in the diamine moiety results in the lower refractive index of the 6FDA/BAPN (d) than that of the 6FDA/BATB (a). As for the case of the 6FDA/BAPPH (c), both the large steric volume of hexafluoroisopropyl group and the small electronic polarizability of the fluorine substitution results in the lowest refractive index among these polyimides. The incorporation of the silica moiety reduces the refractive indices of the hybrid materials because of the low refractive index of the silica (1.44).

The optical losses of the prepared optical waveguides at $1310 \mathrm{~nm}$ measured by the cut-back method are in the range of $1.2-2.7 \mathrm{~dB} / \mathrm{cm}$ for the studied polyimides, and $0.5-$ $2.1 \mathrm{~dB} / \mathrm{cm}$ for the studied polyimide/silica hybrids, as shown in Table 1. The intrinsic optical loss could be investigated by the NIR absorption spectra of the studied materials. Fig. 9 shows the NIR spectra of the prepared

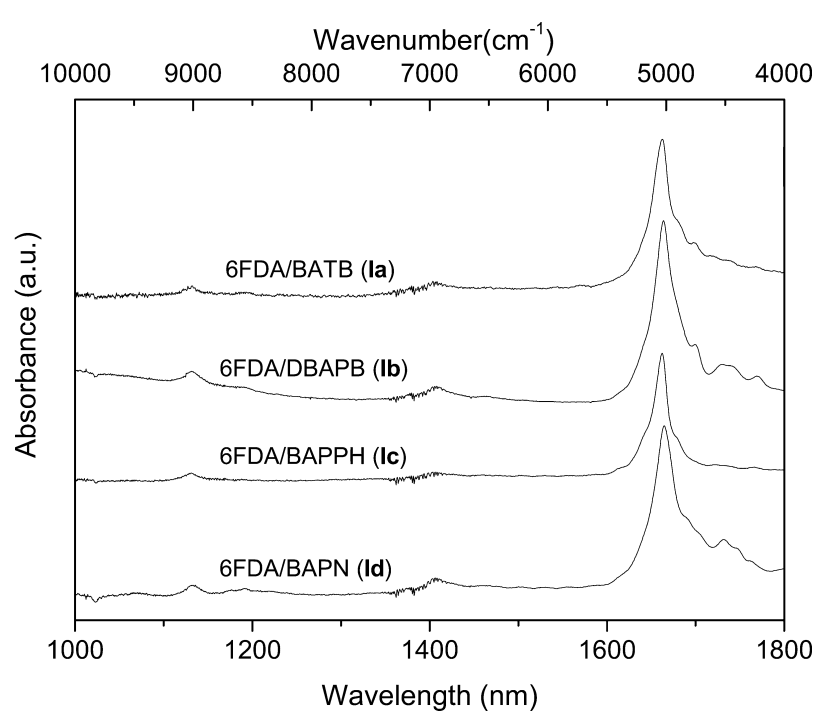

Fig. 9. Near-infrared absorption spectra of the prepared polyimides Ia-Id.

polyimides (Ia), (Ib), (Ic), and (Id). There are three major absorption bands shown in the spectra: the first overtone of the $\mathrm{C}-\mathrm{H}$ stretching vibration band $(1600-1700 \mathrm{~nm})$, the combination of the $\mathrm{C}-\mathrm{H}$ stretching and bending bands $(1350-1450 \mathrm{~nm})$, and the second overtone of the $\mathrm{C}-\mathrm{H}$ stretching band $(1100-1160 \mathrm{~nm})$. The absorption bands shown in Fig. 9 are similar to those reported in the literature [6]. Hence, the intrinsic optical loss of the prepared polyimide based waveguides at $1310 \mathrm{~nm}$ is primarily contributed from the combination band of $\mathrm{C}-\mathrm{H}$ stretching and bending bands, and the second overtone of $\mathrm{C}-\mathrm{H}$ stretching vibration. As shown in Table 1, the optical loss of the prepared waveguide is generally proportional to the $\mathrm{C}-$ $\mathrm{H}$ number density in the molecular structure except for the case of the 6FDA/DBAPB (b). The high optical loss in the 6FDA/DBAPB (b) based waveguide was probably due to the boundary imperfection between the core and the cladding layers. The incorporation of the silica moiety into the polyimides reduces the optical losses because it lowers the $\mathrm{C}-\mathrm{H}$ number density in the molecular structure. It also suggests that the relatively small silica domain for low scattering loss in the prepared hybrid films.

\section{Conclusions}

A series of new polymer-silica hybrid materials was successfully prepared through the intrachain coupling by 3aminopropyl trimethoxysilane (APrTEOS) and interchain hydrogen bonding by $\gamma$-glycidyloxypropyltrimethoxysilanes (GOTMS). The prepared hybrid films were homogeneous and thermally stable. The thermal properties of the organo-soluble polyimides were significantly enhanced by only hybridizing $6.30-7.99 \mathrm{wt} \%$ of silica. It was found that the intrachain chemical bonding could effectively enhance the glass transition temperature or CTE in comparison with the interchain interaction. The prepared hybrid films 
had a low dielectric constant, tunable refractive index and high optical transparence, which could have potential applications for optoelectronic devices.

\section{Acknowledgements}

We thank the financial supports from the National Science Council (NSC90-2216-E002-022 and NDL91S-C055) and the Ministry of the Economic Affairs (Contract 91EC-17-A-08-S1-0015) of Taiwan, ROC.

\section{References}

[1] Laine RM, Sanchez C, Brinker CJ, Giannelis E, Organic/inorganic hybrid materials, vol. 519. Warrendale, PA: Materials Research Society; 1998. Kelin LC, Francis LF, De Duire MR, Mark JE, Organic/inorganic hybrid materials II; materials, vol. 576. Warrendale, PA: Materials Research Society; 1999. Laine RM, Sanchez C, Brinker CJ, Giannelis E, Organic/inorganic hybrid materials-2000, vol. 628. Warrendale, PA: Materials Research Society; 2000.

[2] Sanchez C, Lebeau B. MRS Bull. 2001;26:377.

[3] Kagan CR, Mitzi DB. Science 1999;286:945.

[4] Huynh WU, Dittmer JJ, Alivisatos AP. Science 2002;295:2425.

[5] Tessler N, Medveder V, Kazes M, Kan S, Banin U. Science 2002;295: 1506.

[6] Chang CC, Chen WC. Chem Mater 2002; 14:4242.

[7] Hedrick JL, Cha HJ, Miller RD, Yoon DY, Brown HR, Srinivasan S,
Di Pietro R, Cook RF, Hummel JP, Klaus DP, Liniger EG, Simonyi EE. Macromolecules 1997;30:8512.

[8] Lee LH, Chen WC. Chem Mater 2001;11:1137.

[9] Nandi M, Conklin JA, Salvati L, Sen A. Chem Mater 1991;3:201.

[10] Morikawa A, Yamaguchi H, Kakimoto M, Imai Y. Chem Mater 1994; 6:913.

[11] Wang S, Ahmad Z, Mark JE. Chem Mater 1994;6:943.

[12] Schrotter JC, Smaihi M, Guizard C. J Appl Polym Sci 1996;61:2137.

[13] Srinivasan SA, Hedrick JL, Miller RD, Di Pietro R. Polymer 1997;38: 3129.

[14] Sysel P, Pulec R, Maryska M. Polym J 1997;29:607.

[15] Chen Y, Iroh JO. Chem Mater 1999;11:1218.

[16] Wu KH, Chang TC, Wang YT, Chiu YS. J Polym Sci, Part A: Polym Chem 1999;37:2275.

[17] Hsiue GH, Chen JK, Liu YL. J Appl Polym Sci 2000;76:1609.

[18] Mascia L, Kioul A. Polymer 1995;36:3649.

[19] Ahmad Z, Mark JE. Chem Mater 2001;13:3320.

[20] Tsai MH, Whang WT. Polymer 2001;42:4197.

[21] Cornelius CJ, Marand E. Polymer 2002;43:2385.

[22] Shang XY, Zhu ZK, Yin J, Ma XD. Chem Mater 2002;14:71.

[23] Liaw DJ, Liaw BY. Polym J 1996;28:970.

[24] Liaw DJ, Liaw BY, Jen MQ. Polymer 1998;39:1597.

[25] Liaw DJ, Wang KL. J Polym Sci, Part A: Polym Chem 1996;34:1209.

[26] Liaw DJ, Liaw BY. Polym J 1999;31:1270.

[27] Coburn JC, Pottiger MT, Noe SC, Senturia SD. J Polym Sci, Part B: Polym Phys 1994;32:1271.

[28] Pottiger MT, Coburn JC, Edman JR. J Polym Sci, Part B: Polym Phys 1994;32:825.

[29] Maier G. Prog Polym Sci 2001;26:3.

[30] Van Krevelen DW. Properties of polymers, 3rd ed. Amsterdam: Elsevier; 1997. Chapter 10. 